Though I have never seen nasal or antroethmoidal cancer arising in any patient within Britain who had used snuff, it is a possible explanation for the extraordinarily high incidence of upper jaw neoplasms in the Bantu tribes of the Transvaal, among whom the use of indigenous snuff is widespread. Campbell and Cooper found as much 3:4 benzpyrine in Zulu snuff, which contains charred aloe stems as well as tobacco, as in cigarette smoke condensate. ${ }^{+}$Epidemiological studies, and my own observations in South Africa, support the view that prolonged usage of this carcinogenic snuff is the prime aetiological factor in the production of this highly malignant neoplasm.

Within the United States and Scandinavia snuff dipping is the predominant form of snuff use. "Wet snuff" is placed between the lower lip or buccal mucosa and gums. In many ways this is similar to the use of "pan" or the many other tobacco concoctions that are used within the mouth throughout central and southern Asia. All contain tobacco, but "wet" snuff contains not only nitrosonornicotine but at least 19 other varieties of nitrosamines as well as polycyclic aromatic hydrocarbons. Perhaps more important than chemical analysis and animal experiments of doubtful relevance is the epidemiological evidence of a high incidence of carcinoma at the site of these "implants." In Ceylon and Bombay, where the quid is between cheek and gum, so is the cancer. Where it is held under the tongue, half the cancers affect the anterior tongue. Similar evidence has been available for many years from studies within the southern states of the United States. Snuff dipping has long been a popular practice in these regions, particularly among women. Rosenfield and Callaway found that $90 \%$ of their women patients with oral cancer were habitual users of snuff. ${ }^{5}$ This association has been recognised by most surgeons working in these areas but it is important to remember that such patients may have used snuff for as long as 40 to 60 years. When there is an association with pungent diet, poor oral hygiene, and malnutrition the incidence of cancer may be even higher and the period of exposure much shorter. In my personal experience of 117 patients with cancer of the buccal mucosa, anterior tongue, or floor of mouth I have found a history of snuff dipping only in those from Asia or India. Fortunately dipping is not common in the indigenous or immigrant populations of Britain.

In the United States there is some evidence of a move among young people from cigarette smoking to chewing tobacco or snuff dipping, and this is now threatening in Britain. We should remember that the local effects of snuff on the gums are well recognised-as is the risk of nicotine addiction in the young. Some people seem not to accept that the long term carcinogenic effects of snuff in the mouth would be the same in Britain as those already documented in the United States as well as elsewhere in the world. The time scale may prove to be longer than for tobacco induced lung cancer, but the results of treatment of oral cancer are little better. Tobacco in all its forms is dangerous, and subtle advertising campaigns should not be allowed to confuse the issue. The United Kingdom Coordinating Committee in Cancer Research called last week ( $p 000$ ) for a ban on the import, manufacture, and sale of snuff.

D F N HARRISON

Professor of Laryngology and Otology,

Institute of Laryngology and Otology,

London WCIX 8EE

\footnotetext{
I Russell MAM, Jarvis MS, Devitt G, Feyerabend C. Nicotine intake by snuff users. Br Med $\mathcal{J}$ 1981;283:814-7.

2 Harrison DFN. Snuff-its use and abuse. Br Med f 1964;ii:1649-51.

3 Root HD, Aust JB, Sullivan A. Snuff and cancer of the ear. N Engl f Med 1960;262:819-20.

4 Campbell JM, Cooper RL. The presence of 3.4 Benzypyrine in snuff associated with a high incidence of cancer. Chemistry and Industry 1955;33:64-6.
}

5 Rosenfeld L, Calloway J. Snuff dippers cancer. Am 7 Surg 1963;106:840-4

\title{
Management of infection in the neutropenic patient
}

\author{
ROBERT E MARCUS, JOHN M GOLDMAN
}

Some reversible depression of the bone marrow is an inevitable consequence of many chemotherapy regimens used in oncology. Such periods of neutropenia are usually short; if prolonged they would probably lead to reduction in the dosage of cytotoxic drugs for later courses. In the management of acute leukaemia, however, and more recently in lymphoma and some solid tumours long periods of marrow hypoplasia and neutropenia are the consequence of deliberate attempts to maximise the kill of tumour cells.

These periods of neutropenia, lasting up to four weeks, are also seen after autologous and allogeneic bone marrow transplantation and carry the risk of severe bacterial, fungal, and viral infection. The incidence and severity of these infections are greater than those seen in chronic neutropenic states such as aplastic anaemia since chemotherapy and radiotherapy damage the membranes of the oropharynx, gut, and lung and thereby permit predominantly Gram negative organisms to enter the systemic circulation or the lung parenchyma more readily. By contrast patients with neutropenia due to severe aplastic anaemia rarely suffer from serious infections with Gram negative organisms, their frequency being related to the absolute monocyte count. ${ }^{1}$

This combination of damage to membranes and suppression of residual haemopoiesis renders patients with leukaemia particularly susceptible to severe infections, many of which are due to endogenous gastrointestinal organisms. ${ }^{2}$ This has led several groups to attempt to reduce the level of microbial flora in the gut with combinations of non-absorbable antibiotics. ${ }^{3}$ Some centres persist with this approach, but many have rejected it for three reasons: firstly, the necessary 
antibiotics are unpalatable and poorly tolerated by patients already nauseated by chemotherapy; secondly, because true "sterilisation" of the gut is difficult to achieve even when compliance is good; and, thirdly-and perhaps most important - because studies on animals suggest that elimination of both anaerobes and aerobes permits very low numbers of exogenous Gram negative organisms to colonise the gastrointestinal tract and to cause clinical infection. This concept-that the presence of anaerobic organisms may protect against exogenous pathogens-has been termed "colonisation resistance", and has led to the adoption of selective, aerobic decontamination in order to prevent systemic infection by Gram negative organisms in the gut. Cotrimoxazole is chosen most frequently for this purpose, since it is active against Gram negative organisms as well as against Haemophilus influenzae and Streptococcus pneumoniae. ${ }^{56}$ It also provides effective prophylaxis against Pneumocystis carinii in the recipients of bone marrow transplants and in children with acute lymphoblastic leukaemia. ${ }^{7}$ This approach is not without problems during second or subsequent courses of intensive chemotherapy, since organisms resistant to cotrimoxazole are common ${ }^{8}$ and alternative agents such as colistin may have to be added or substituted. The risk of fungal colonisation may be reduced by adequate daily doses of oral amphotericin B and nystatin, or by ketoconazole, or by small doses of amphotericin B given intravenously two or three times a week.

Further attempts to reduce the risk of infection in this group of patients include the use of a sterile diet and protective isolation. The evidence on the effectiveness of these measures is conflicting, since the various studies that have been reported differ in the degree of isolation and in the type of gut decontamination used. Simple hand washing by medical and nursing attendants and laminar airflow facilities, when available, seem effective in reducing infection due to exogenous organisms. ${ }^{9}$

Patients who go home with indwelling Hickman catheters often have positive blood cultures on readmission. ${ }^{10}$ The organism is usually Staphylococcus epidermidis, ${ }^{11}{ }^{12}$ but other pathogens, such as Klebsiella sp, Escherichia coli, and Str viridans, have been isolated from asymptomatic patients, both from the line and peripheral blood; the incidence of such colonisation rises during second and subsequent admissions for consolidation chemotherapy, and "line" infections are an important cause of low grade fever in the neutropenic phase requiring specific treatment. ${ }^{13}$

The clinical observation that the cause of fever in neutropenic patients, when it is identified, is frequently an organism isolated from the faeces or a rectal swab a few days before the onset of the fever emphasises the importance of "surveillance" cultures. ${ }^{14}$ These should ideally be taken from the faeces and also the nose, throat, groin, and the urine on admission and weekly or twice weekly thereafter; if full facilities are not available regular culture of at least the faeces or rectal swabs is essential.

Fever that occurs despite prophylactic measures soon after the onset of neutropenia is often the only physical sign of infection and should be treated urgently with systemic antibiotics after blood cultures have been taken from both the Hickman line and a peripheral vein and the results of surveillance cultures have been analysed. Irreversible septicaemic shock may otherwise supervene within hours; afebrile patients who have symptoms and signs of septicaemia, especially those who are taking or have recently taken steroids, should be treated in the same way.

Full physical examination including of the mouth and perianal region and a chest $x$ ray film should be performed in an attempt to identify a focus of sepsis, but commonly there are no clues to either the site of sepsis or the nature of the infecting organism; indeed, in over four fifths of all febrile episodes in neutropenic patients no organism is ever identified. $^{15}$ Treatment should, therefore, be started with an antibiotic regimen with the broadest possible spectrum, though in the absence of definite clinical or bacteriological evidence antianaerobic cover is not essential at first. A standard combination in many centres is an aminoglycoside-for example, amikacin, gentamicin, netilmicin, or tobramycin-plus a semisynthetic penicillin with antipseudomonal activity-for example, azlocillin or piperacillin-or a cephalosporin-for example, cefotaxime, cefoxitin, or cefuroxime. ${ }^{16}{ }^{17} \mathrm{~A}$ recent prospective controlled clinical trial of piperacillin, netilmicin, and cefotaxime versus the new extended spectrum cephalosporin, ceftazidime, showed no differences in the response rate or morbidity between the two groups, ${ }^{18}$ but some clinicians may continue to prefer to use at least two effective antibacterial agents for initial "blind" treatment in these patients. If Staph epidermidis or other Gram positive organisms have been isolated from the Hickman line on admission then vancomycin should be added to the antibacterial regimen.

Patients who respond should remain on antibiotics until either their neutrophil counts recover $\left(>0.5 \times 10^{9} / 1\right)$ or until they have been afebrile for at least five days; these events will often coincide. Conversely, patients who deteriorate rapidly may need to be treated with additional antibiotics with broad spectrum activity. Others who do not respond may be reassessed at 72 hours, when bacteriological studies can be reviewed and antibiotics added if resistant or partially resistant organisms have been isolated. If Gram negative organisms continue to be isolated from the Hickman line it should be removed, but line sepsis with Gram positive organisms may be controlled with vancomycin without removing it. ${ }^{19}$ If fever persists after broad spectrum antibacterial treatment for 72 hours with no clinical or laboratory evidence of bacterial infection it is unlikely to be bacterial, and empirical antifungal treatment with amphotericin B should be considered if the neutropenia is likely to persist more than five days. ${ }^{20}$ Though newer imidazole derivatives such as itraconazole may be shown to be useful, amphotericin $B$ is still the only agent with proved efficacy against fungal infection in patients with neutropenia. Candidal infection may then respond, but infection with aspergillus may be impossible to eradicate until neutrophils return, and high doses of amphotericin B (up to $1 \mathrm{mg} / \mathrm{kg}$ a day) may be required to control invasive pulmonary aspergillosis. ${ }^{21}$

\section{Granulocyte transfusions}

The place of granulocyte transfusions is not clear. ${ }^{22}$ Early reports suggested a reduction in the mortality of neutropenic patients who received them during febrile episodes, ${ }^{23}{ }^{24}$ but a more recent prospective trial concluded that there was no difference in mortality whether or not granulocytes were administered. ${ }^{25}$ Variability in the numbers of granulocytes transfused and the use of more effective antibiotic combinations in recent years may account for this discrepancy. Where available, the transfusion of large numbers of irradiated granulocytes derived from a cell separator from a patient with chronic myeloid leukaemia may reduce fever dramatically, though transiently, in infected patients with neutropenia. ${ }^{26}$

The infections that occur in recipients of bone marrow 
transplants during the neutropenic phase are similar to those seen in other neutropenic patients, but the risk of bacterial infection may remain high even when neutrophil counts return to normal. ${ }^{27}$ Oral antibiotic prophylaxis with phenoxymethylpenicillin or co-trimoxazole should, therefore, be continued for some years-or for life. Cell mediated and humoral immunity remain depressed for long periods. The patient is then susceptible to overwhelming viral infections. The most frequent of these are with the herpes group viruses,${ }^{28}$ although infection with adenovirus ${ }^{29}$ and papovavirus is being reported increasingly often. ${ }^{30}$ Herpes simplex infections usually occur within the first months after bone marrow transplantation. Classically these affect the oropharynx and oesophagus; infections of the central nervous system are also well recognised. Such infections usually respond well to acyclovir, but herpes encephalitis still carries a substantial mortality. Infections with varicella zoster classically occur between three months and one year after bone marrow transplantation. Effective symptomatic relief and clearance of lesions may also be obtained with acyclovir.

Pneumonitis due to cytomegalovirus infection is now the single most important cause of death in bone marrow transplant recipients. Preliminary results report some success in early cases using cytomegalovirus hyperimmune globulin $^{31}$; foscarnet may also prove useful for such patients. ${ }^{32}$ These preliminary results need to be confirmed, preferably by randomised trials. Human T cell lymphotrophic virus III infection has been reported in two patients after bone marrow transplantation, but no effective treatment is available. $^{33}$

1 Keidan AJ, Tsatalas C, Cohen J, Cousins S, Gordon-Smith EC. Infective complications of aplastic anaemia. Br $\mathcal{F}$ Haematol 1986 (in press).

2 Young LS. Gram-negative bacillary colonization and bacteremia in the immunocompromised host. $\mathcal{F}$ Infect Dis 1982;10:319-23.

3 Schimpff SC, Greene WH, Young LM, et al. Infection prevention in acute non-lymphocytic leukemia: laminar air-flow, reverse isolation and non-absorbable antibiotic prophylaxis. $A n n$ Intern Med 1975;82:351-8.

4 Van Der Waaij, Berghuis JM, Lekkerkerk JEC. Colonization resistance of the digestive tract of mice during systemic antibiotic treatment. $f$ Hyg (Lond) 1972;70:605-10.

5 Young LS. Nosocomial infections in the immunocompromised adult. Am f Med 1981;70:398-404.

6 Starke ID, Donnelly JP, Catovsky D, et al. Cotrimoxazole alone for the prevention of bacterial infection in patients with acute leukaemia. Lancet 1982;ii:5-6.

7 Hughes WT, McNabb PC, Makres TD, et al. Efficacy of trimethoprim and sulfamethoxazole in the prevention and treatment of Pneumocystis carinii pneumonitis. Antimicrob Agents Chemother 1974;5:289-93.

8 Murray BE, Rensimer ER, Dupont HL. Emergence of high level trimethoprim resistance in fecal E coli during oral administration of trimethoprim or trimethoprim/sulfamethoxazole. $N$ Engl $\mathcal{F}$ Med 1982;306:130-5.

9 Scrimff S. Infection in the immunocompromised host. In: Remington JS, Swartz MN. Current clinical topics in infectious diseases. New York: McGraw Hill, 1983:156-83.

10 Donnelly JP, Cohen J, Marcus RE, Guest J. Bacteraemia and Hickman catheter. Lancet 1984;i:48.

11 Sanz MA, Such M, Rafecas FJ, Martin G, Santos G. Staphylococcus epidermidis infections in acute myeloblastic leukaemia patients fitted with Hickman catheters. Lancet 1983;ii:1192-3.

12 Fischer GW, Zawadsky $P$, Shanks D, et al. Bacterial pathogens in patients with indwelling venous catheters. Lancet 1985; ; 1284

13 Wade JC, Schimpff SC, Newman KA, Wiernick PH. Staphylococcus epidermidis: an increasing cause of infection in patients with granulocytopenia. Ann Intern Med 1982;97:503-8.

14 Gaya $\mathrm{H}$. Rational basis for the choice of regimens for empirical therapy of sepsis in granulocytopenic patients. Clin Haematol 1984;13:573-86.

15 The EORTC International Project Group. Three antibiotic regimens in the treatment of infection in febrile granulocytopenic patients with cancer. $\mathcal{I}$ Infect Dis 1981;137:14-29.

16 Pizzo PA, Robichaud KJ, Gill FA, Witesby FG. Empiric antibiotic and antifungal therapy for cancer patients with prolonged fever and granulocytopenia. Am $\mathcal{F}$ Med 1982;72:101-11.

17 Klastersky J. Management of infection in granulocytopenic patients. $\mathcal{J}$ Antimicrob Chemother 1983;12:102-4.
Thus the pattern of infection in neutropenic patients is altering: a greater proportion of Gram positive infections is now observed, but bacterial infection overall is becoming a less important cause of morbidity and mortality. There are several reasons for this. The duration of neutropenia is more predictable, and in most patients peripheral blood counts recover completely after each course of chemotherapy. The newer broad spectrum antibiotics are very active against both Gram positive and Gram negative organisms, and the increased use of surveillance cultures enables rational treatment with antibiotics to be given at the onset of fever. It is still possible, however, that the pattern of bacterial resistance to antibiotics may change abruptly in the future. An important problem not solved is the lack of effective nontoxic antifungal and antiviral agents. The management of infection in neutropenic patients will, therefore, continue to demand our attention for some while.

ROBERT E MARCUS

Senior Registrar,

Department of Haematology,

Royal Free Hospital,

London NW3 2QG

JOHN M GOLDMAN

Honorary Consultant Physician,

Hammersmith Hospital and

Royal Postgraduate Medical School, London W120HS

Correspondence to Dr Marcus.

18 Donnelly JP, Marcus RE, Goldman JM, et al. Ceftazidime as first-line therapy for fever in acute leukaemia. Journal of Infection 1985;ii:205-15.

19 Winston DT, Dudnick DV, Chapin M, Ho WG, Gale RP, Martin WJ. Coagulase-negative staphylococcal bacteraemia in patients receiving immunosuppressive therapy. Arch Intern Med 1983;143:32-5.

20 Cohen J. Empirical antifungal therapy in neutropenic patients. $f$ Antimicrob Chemother 1984;13:409-11.

21 Aisner J, Schimpff SC, Wiernik PH. Treatment of invasive aspergillosis: early diagnosis and response to treatment. Ann Intern Med 1977;86:539-43.

22 Strauss RG. Granulocyte transfusion therapy. Clinics in Oncology 1983;2:635-55.

23 Graw RG, Herzig G, Perry S, Henderson ES. Normal granulocyte transfusion therapytreatment of septicemia due to gram-negative bacteremia. N Engl f Med 1972;287:367-71.

24 Herzig R, Gerzig G, Graw RG, Bull MI, Ray KK. Efficacy of granulocyte transfusion therapy for gram-negative sepsis-a prospective randomised controlled study. N Engl f Med 1977;296 $701-5$.

25 Winston DT, Ho WG, Gale RP. Therapeutic granulocyte transfusions for documented infections a controlled trial in 95 infective Gram-negative episodes. Ann Intern Med 1982;97:509-18.

26 Lowenthal RM, Grossman L, Goldman JM, et al. Granulocyte transfusions in treatment of infections in patients with acute leukaemia and aplastic anaemia. Lancet 1975;i:353-8.

27 Meyers JD, Atkinson K. Infection in bone marrow transplantation. Clin Haematol 1983;12: 791-811.

28 Meyers JD, Flournoy N, Thomas ED. Infection with herpes simplex virus and cell mediated immunity after marrow transplant. I Infect Dis 1980;142:338-46.

29 Tolken RH, Bishop CA, Townsend TR, et al. Infectious gastroenteritis in bone marrow transplant recipients. N Engl I Med 1982;306:1009-12.

30 O'Reilly RJ, Lee FK, Grossbard E, et al. Papovavirus excretion following bone marrow transplantation: incidence and association with hepatic dysfunction. Transplant Proc 1981;13 262-6.

31 Blacklock HA, Griffiths P, Stirk P, Prentice HG. Specific hyperimmune globulin for cytomegalovirus pneumonitis. Lancet 1985; ii: 152-3.

32 Apperley JF, Marcus RE, Goldman JM, Wardle DG, Gravett PJ, Chanas A. Foscarnet for cytomegalovirus pneumonitis. Lancet 1985; 151 .

33 Gluckman E, Spire B, Gluckman J, et al. Two cases of acquired immunodeficiency syndrome (AIDS) after allogeneic bone marrow transplant (BMT): transmission of LAV by healthy marrow donors [Abstract]. Exp Hematol 1985;13:325. 